\title{
0 impacto da extensão universitária sobre a formação acadêmica em Odontologia ${ }^{*}$
}

\section{Introdução}

Conforme o Plano Nacional de Extensão Universitária, elaborado no Fórum de Pró-Reitores de Extensão das Universidades Públicas Brasileiras (Brasil, 2002a), a extensão universitária é o processo educativo, cultural e científico que articula o ensino e a pesquisa de forma indissociável e viabiliza a relação transformadora entre universidade e sociedade. Apresenta-se, ainda, como uma das práticas acadêmicas com potencial para interpretar, na universidade, as demandas que a sociedade impõe, uma vez que permite socializar o conhecimento e promover o diálogo entre o saber científico e o saber popular. Entende-se, aqui, que esta aproximação e (re)significação dos saberes deva ser exposta como uma importante estratégia para a ação e a transformação da realidade em saúde de diferentes populações, num verdadeiro processo de mudança do método formativo tradicional.

Especificamente para o campo acadêmico, verifica-se uma preocupação crescente com o modelo formador do profissional em saúde, na qual, cada vez mais, se configura a necessidade de profissionais aptos a contribuírem com a sociedade num contexto de profundas mudanças, não somente em seu próprio campo profissional, mas, também, nos campos político e social (Costa, 2007). Neste sentido, a extensão universitária assume o papel de potencializadora desta relação, por meio da diversificação de cenários e metodologias de aprendizagem, implementando novos espaços de discussão, análise e reflexão das práticas no cotidiano do trabalho e dos referenciais que as orientam (Ferreira Fiorini, Crivelaro, 2010; Ceccim, 2005; Feuerwerker, Costa, Rangel, 2000), reafirmando, ainda, o seu compromisso na formação acadêmica humana e social.

A partir do reconhecimento da importância de ações extensionistas para docentes, discentes, técnicos e sociedade, com vistas a potencializar e ampliar os patamares de qualidade das ações institucionais, o Departamento de Odontologia da Universidade Estadual de Ponta Grossa (UEPG) desenvolve uma iniciativa inovadora intitulada 'Projeto nós na rede: contribuições da Odontologia para educação, prevenção e manutenção da saúde'. Como principais objetivos, destacam-se: atenuar a carência de políticas de apoio voltadas para a comunidade acadêmica da UEPG, especialmente em situação de vulnerabilidade social, e a sua
1,3,4 Departamento de Odontologia Universidade Estadual de Ponta Grossa. Rua Dr. Paula Xavier, 909. Ponta Grossa, PR, Brasil. $84010-270$ cfadel@uepg.br 2 Mestranda em Odontologia Preventiva e Social, Faculdade de Odontologia de Araçatuba, UNESP - Univ Estadual Paulista. 
comunidade externa, no âmbito da saúde bucal, e oportunizar, ao acadêmico de Odontologia, uma vivência prática de atenção coletiva em saúde. Este projeto atua como instrumento viabilizador da estratégia de Promoção da Saúde (Brasil, 2010), disseminando informações, com ênfase no empoderamento e na autonomia dos sujeitos, realizando ações de cunho educativo e preventivo em saúde bucal, e acolhendo necessidades odontológicas curativas.

Percebendo a extensão universitária como uma atividade capaz de imprimir novos rumos à formação acadêmica, constituindo-se instrumento indispensável de aprendizagem e de formação profissional e pessoal, o presente estudo buscou avaliar a contribuição da extensão universitária, por meio do projeto 'Nós na Rede', na formação e história de vida de estudantes do curso de Odontologia da UEPG.

\section{Metodologia}

Este trabalho qualitativo, classificado como descritivo-exploratório, foi aprovado pelo Comitê de Ética em Pesquisa da UEPG, segundo a Resolução 196/96 do Conselho Nacional de Saúde.

\section{Os informantes}

Constituíram-se sujeitos desta pesquisa os acadêmicos de Odontologia que participaram do projeto de extensão 'Nós na rede', no período compreendido entre abril de 2011 e abril de 2012, quando em acordo com sua participação e sob garantia de total sigilo e anonimato. Como não houve recusa por parte dos informantes, nove acadêmicos compuseram a amostra final.

\section{O projeto}

O projeto extensionista 'Nós na rede' se dedica ao acolhimento das demandas educativas, preventivas e curativas, em saúde bucal, da comunidade acadêmica da UEPG e de sua comunidade externa em geral, atuando em três frentes de trabalho. Uma delas refere-se à capacitação continuada dos extensionistas, efetivada por meio de reuniões periódicas, com o intuito de fomentar a discussão sobre diferentes potenciais humanos e estratégias de atuação junto a pares acadêmicos e comunidade externa, além de questões técnicas e científicas específicas da saúde bucal em âmbito coletivo. Outra é destinada à atenção preventiva e curativa em saúde bucal, aos acadêmicos da UEPG, a qual é desenvolvida semanalmente em dispensário odontológico da própria instituição. Durante esta etapa, os extensionistas realizam, primeiramente, atividades educativas em saúde bucal utilizando-se do diálogo, de vídeos e de materiais educativos impressos, e, posteriormente, procedem à realização de criterioso protocolo clínico, com ampla anamnese e com o reconhecimento de necessidades odontológicas curativas. A terceira vertente contempla a disseminação de informações junto à comunidade externa, rotineiramente viabilizada por meio de parcerias com instituições públicas locais e regionais, desenvolvidas em diversos espaços sociais, onde professores e alunos de Odontologia buscam desenvolver habilidades pessoais e a ampliação das concepções humanas sobre a saúde e a doença, capacitando os indivíduos e tornando-os aptos a minimizarem as suas situações de vulnerabilidade pessoal e coletiva, no âmbito da saúde bucal.

\section{Obtenção das informações}

Como subsídio para a coleta de dados, utilizou-se a técnica denominada grupo focal, estruturada, inicialmente, por Merton et al. (1956). Esta é uma modalidade científica da pesquisa qualitativa utilizada no entendimento das diferentes percepções e atitudes acerca de um fato, prática, produto ou serviço (Iervolino, Pelicioni, 2001). A essência do grupo focal consiste na interação entre os participantes e o pesquisador, que objetiva colher dados a partir da discussão focada em tópicos específicos e diretivos (Iervolino, Pelicioni, 2001). 
Desta forma, no presente estudo, um único pesquisador previamente treinado e calibrado utilizou-se de um roteiro de tópicos, elaborado no sentido de orientar uma conversa, visando apreender o ponto de vista dos sujeitos entrevistados sobre temas preestabelecidos (motivação para participar, entraves/ contribuições, especificidades/peculiaridades, considerações); ou seja, permitiu-se o livre discurso e, ao mesmo tempo, o delineamento da conversa, buscando manter a entrevista sintonizada com os objetivos da pesquisa.

A técnica de entrevista em grupo focal foi realizada em espaço neutro, externo às dependências da UEPG, visando a liberdade de expressão dos informantes. A entrevista teve duração de setenta minutos e foi gravada, para que não se perdesse nenhuma informação que o entrevistado pudesse espontaneamente dar, bem como para se obter, juntamente com as palavras, a emoção e/ou sentimento passado pelo entrevistado. Posteriormente, os relatos foram transcritos e analisados.

\section{Análise das informações}

O material produzido por meio de entrevista foi tratado de acordo com a técnica de análise do Discurso do Sujeito Coletivo (DSC), proposta por Lefèvre (Lefèvre, Lefèvre, 2003). Consiste na reunião, de um só discurso-síntese, de vários discursos individuais emitidos como resposta a uma mesma questão de pesquisa, por sujeitos social e institucionalmente equivalentes ou que fazem parte de uma mesma cultura organizacional e de um grupo social homogêneo.

Os relatos obtidos nas entrevistas foram analisados para a identificação das expressões-chave de conteúdo similar, e identificação das ideias centrais, para, posteriormente, formular-se uma síntese única originária dos discursos. Os DSCs foram discutidos com suporte da literatura científica.

\section{Resultados e discussão}

Do total de acadêmicos entrevistados $(n=9)$, oito pertenciam ao gênero feminino e um ao gênero masculino, distribuídos ao longo do terceiro e quarto anos do curso de Odontologia. A faixa etária média dos participantes foi de vinte anos.

Na sequência, expõem-se as temáticas extraídas, as ideias centrais e os discursos resultantes da análise, bem como a discussão com base em referencial teórico.

\section{Tema 1 - Por que estou aqui?}

\section{Ideia central - Rompendo com paradigmas pedagógicos e curriculares tradicionais}

DSC - Eu queria fazer alguma coisa além do teórico, algo que fosse fora clínica, fora da aula, fora da cobrança [...] queria ver como seria trabalhar sem tensão, sem a exigência de nota por produção, essa parte [...] eu queria fazer além, mesmo sem saber exatamente como.

O Ensino Superior vivencia, atualmente, um processo de esgotamento do seu modelo tradicional de educação, estando a necessidade de mudanças nessa concepção nas pautas de discussão há algum tempo (Araujo, 2006), apesar dos recentes avanços. Sobretudo quando debate os seus métodos avaliativos nas áreas da saúde e apesar das tentativas de enfoque na 'qualidade' da produção acadêmica; o método quantitativista é ainda uma estratégia que continua fortemente arraigada nas instituições de Ensino Superior. Superar essa dicotomia e mesclar a técnica às relações humanas é um desafio que há tempos se coloca nos currículos de graduação e nas políticas públicas e práticas de saúde (Freitas, Calvo, Lacerda, 2012; Lanzieri et al., 2011; Villa, Aranha, 2009). Este fato contribui para que muitos acadêmicos busquem uma maneira de inovar, capaz de contribuir com as formas alternativas de trabalho e que rompam com as estruturas tradicionais (Lima et al., 2010). A extensão universitária assume uma destas formas, como destacado no discurso acadêmico, uma vez que possibilita ao estudante 
O IMPACTO DA EXTENSÃO UNIVERSITÁRIA ..

(re)produzir, de maneira diferenciada, os conhecimentos adquiridos ao longo da sua graduação e transcender os arraigados processos avaliativos universitários.

\title{
Ideia central - A realização por meio do que é coletivo
}

DSC - Queria vivenciar uma experiência nova e ter a oportunidade de trabalhar com pessoas mais carentes [...] acho que conta muito para a nossa formação [...] a gente se sente útil, ver que está fazendo alguma coisa pela comunidade. Mesmo que seja pouca coisa, mas aquilo a gente vê que vai fazer diferença mesmo que seja na vida de uma pessoa [...] a gente sente que está fazendo nosso papel na sociedade, a gente aprende a ser mais ético e humano também.

Estudos relatam a importância do desenvolvimento de trabalhos de caráter comunitário, uma vez que se trata de um serviço comprometido com a sociedade e alicerçado na liberdade de escolha, o qual busca trazer novos valores e reforçar os existentes na sociedade, para a transformação em um mundo melhor (Reis, 2001).

Para Selliet et al. (2008), quando um indivíduo se propõe a desenvolver atividades coletivas, ele é beneficiado pelo: aprendizado, superação de si mesmo, redimensionamento do cotidiano, encontro com a própria humanidade, despertar da sensibilidade humana, possibilidade de aplicar os conhecimentos adquiridos durante a graduação, e criação de vínculos com a comunidade. Ainda, relaciona-se a sensação da realização pessoal e da satisfação íntima pelo prazer e alegria em servir (Selli et al., 2008; Drury, Reicher, 2005; Reis, 2001).

Corroborando com o presente estudo, Reis (2001) relata ser comum o engajamento de estudantes em atividades voluntárias, não apenas para exercitar a caridade, mas como uma forma de cidadania e reconhecimento da importância da sociedade ao longo de sua vida acadêmica.

\section{Ideia central - O desejo de ser reconhecido e valorizado}

\author{
DSC - Você vira referência na sala de aula, perante os colegas [...] eles não têm noção às \\ vezes do que a gente faz e encontra, mas sabem que é diferente [...] a gente se sente \\ importante, quando tem eventos fora da universidade somos nós que vamos representar a \\ instituição [...] é gostoso se sentir referência de um projeto de extensão voltado para a \\ comunidade e ter mais responsabilidade! [...] conviver com os professores de maneira mais \\ informal também é bem bacana.
}

De acordo com Hallack e Silva (2005), qualquer que seja o trabalho numa organização, instituição, ele, no mínimo, proporcionará ao sujeito um bem precioso: a possibilidade de identificação social e cultural através da incorporação de valores. Os extensionistas, em seus discursos, traduzem os trabalhos por eles desenvolvidos em sentimentos que tangem a necessidade de identificação, idealização, valorização e reconhecimento pessoal. O respeito e a confiança estabelecidos entre professor-aluno e aluno-instituição, o orgulho de fazer algo importante para si e para a sociedade, e o prazer em enfrentar e vencer desafios, também são positivamente destacados.

\section{Tema 2 - Mãos à obra}

\section{Ideia central - Os inevitáveis entraves e frustrações}

DSC - [...] minha frustração é quando queremos abordar uma pessoa no aspecto não clínico e ela não tem interesse, mas isso não é nossa culpa, nós queríamos levar informação, mas tem aqueles que não estão muito afim de ouvir [...] mas se apenas um vai ouvir, temos sempre que nos focar naqueles que fazem o nosso esforço valer a pena! 
Trabalhar com ações informativas que demandem a (re)educação da população em termos de mudanças de hábitos é muito difícil, pois envolvem a maneira como as pessoas vivem e entendem a vida, através de uma visão plural e cultural, que consiste em valores, crenças e visões de mundo, situados em um tempo e espaço delimitado (Alves, Aerts, 2011).

Os entraves e limitações aqui expostos, no que se refere à autonomia em saúde dos sujeitos individuais e coletivos, com vistas a sua emancipação e empoderamento pessoal, revelam-se agente de frustração entre os entrevistados. Entretanto, ao exercer o papel de agente dinamizador de conhecimento em saúde, o acadêmico deve agir sobre o outro que se dispõe a receber seus cuidados, ajudando-o a se ajudar, estimulando a capacidade de as pessoas enfrentarem seus problemas, a partir de condições concretas de vida (Santos et al., 2008). Vale ressaltar o reconhecimento da importância dessa missão singular como norteadora na sua formação, por parte dos acadêmicos, apesar do seu desapontamento.

\section{Ideia central - Dançando conforme a música}

DSC - Estamos mais acostumados a trabalhar com crianças, mas o projeto exige todos os ciclos de vida, é diferente com os jovens, por exemplo [...] é muito difícil, porque eles acham que já sabem tudo e a gente teve que desenvolver um jeito de falar que foi um jeito entre amigos sabe, isso foi complicado no começo [...] eu acho que a gente ainda tá engatinhando, mas a gente vai aprendendo a lidar com pessoas de diferentes idades, sexo, classe social, e querendo ou não a gente vai levar isso pra vida [...] é, a gente tem que se preparar para o público alvo, descobrir qual o seu interesse, sua necessidade.

A realidade social, ou seja, a práxis, é determinante das relações sociais, fato que engloba, além dos aspectos demográficos, políticos e econômicos, também particularidades, interesses, crenças, hábitos, pensamentos, valores, normas e comportamentos. Dessa maneira, entende-se que é dentro da realidade de cada ciclo de vida humano que o acadêmico deva compreender e vivenciar as suas distintas implicações socioculturais (Lara et al., 2012), criando um espaço de reflexão crítica, de diálogo e de construção compartilhada do conhecimento (Brasil, 2007). Esse entendimento, com vistas à ação extensionista, é aqui claramente exposto pela percepção acadêmica.

\section{Ideia central - A inevitável troca de saberes}

DSC - Eu acho que com a comunidade a gente aprende bastante, é, aprende muita coisa. Por mais que possa ser crença popular, sempre alguma coisa vai ter de interessante naquilo [...] Acho que a gente tem que usar esses saberes da comunidade pra gente conseguir até transmitir, usar o que eles sabem e embutir alguma coisa a mais pra eles [...] você tem que saber se comunicar pra desmistificar alguma ideia pronta, formada [...] apesar de que o fato da pessoa acreditar mesmo naquilo, ter fé, já ajuda, né? Vai saber...

O saber popular está vinculado a tradições que são conduzidas entre gerações, em que ecoam socialmente e propiciam a cognição de práticas capazes de articular experiências presentes e passadas, estimando a ligação de cada sujeito ao seu mundo, seus valores, saberes e problemas (Lara et al., 2012). Nesta perspectiva, surge a educação para a saúde, caracterizada como veículo integrador dos mais diferentes campos de saberes e práticas humanas. A profícua relação entre o saber científico e o popular é concretizada pelos acadêmicos, os quais evidenciam que o conhecimento precisa ser partilhado entre os diferentes sujeitos.

Segundo Drury e Reicher (2005), uma série de relatos científicos tem demonstrado que esse tipo de atuação educativa junto à comunidade pode gerar experiências de capacitação, formando um lócus de possibilidades, ações e mudanças na forma de pensar e agir, (re)criando cotidianamente novos modos de fazer saúde (Romanholi, Cyrino, 2012). 


\title{
Tema 3 - O subsídio humano
}

\section{Ideia central - Desenvolvendo habilidades profissionais}

\begin{abstract}
DSC - Fora do projeto a gente não vê o paciente como uma pessoa, é só mais um procedimento clínico [...] aqui eu consigo fazer um planejamento e concluir um plano de tratamento[...] a gente consegue integrar os conhecimentos de todas as áreas e ver a aplicação prática do conteúdo teórico, tudo junto [...] e nas ações externas, aprende a trabalhar em equipe e a falar com as pessoas [...] por isso o projeto é importante pra gente, porque daí você aprende a ver tudo de um jeito diferente, sem aquele condicionamento que a gente tem.
\end{abstract}

Na maioria das escolas de Odontologia, o ensino é, ainda, distribuído ao longo do curso, fazendo com que a prática clínica seja desenvolvida de maneira isolada nas disciplinas profissionalizantes, sem integrar os conhecimentos (Arruda et al., 2009; Villa, Aranha, 2009; Santos, 2003). Este fato pode gerar uma fragmentação dos saberes, os quais permanecem isolados uns dos outros (Villa, Aranha, 2009), dificultando a perspectiva de conjunto e de globalização e desfavorecendo a aprendizagem (Santos, 2003), podendo ser constatada, em alguns casos, tanto na formação quanto no exercício profissional (Villa, Aranha, 2009). Portanto, segundo Nóvoa (1995), é importante buscar e valorizar paradigmas de formação que promovam a preparação de profissionais reflexivos, que assumam a responsabilidade do seu próprio desenvolvimento profissional e que participem como protagonistas na implementação de novas formas de integralizar o conhecimento. Nesse discurso, os estudantes percebem, na ação extensionista, a possibilidade de ruptura do enfoque tradicional do ensino e da aplicação lógica e ordenada dos conhecimentos, habilidades e atitudes adquiridos nas diferentes disciplinas, oportunizando, ao paciente, um atendimento de forma integral e mais humanizada.

Os achados aqui expostos corroboram, ainda, com o estudo de Lanzieri et al. (2011), o qual mostra que a extensão universitária é capaz de promover maior convivência, troca de conhecimentos e respeito ao saber alheio, além de facilitar o aprendizado do trabalho em equipe.

\section{Ideia central - Desenvolvendo habilidades pessoais}

DSC- Eu acho que a gente ganha bastante, que a gente consegue ver que a nossa realidade, querendo ou não, é muito diferente do resto das pessoas [...] a gente consegue ver como as pessoas agem, como é a vida delas e acaba dando mais importância para o que tem [...] visualização da realidade do outro ajuda no repensar dos nossos valores humanos [...] nos transforma em pessoas mais sensíveis.

A diversificação de cenários de aprendizagem, muitas vezes trazida pela extensão universitária, se apresenta como um importante meio facilitador de interações mais dinâmicas e verdadeiras entre o aluno e a comunidade (Pereira et al., 2011), proporcionando, ao estudante, a compreensão do mundo de cada indivíduo, as histórias vividas e as suas diversas versões (Romanholi, Cyrino, 2012).

Por meio do estudo de Sanchez, Drumond e Vilaça (2008), constatou-se que a convivência com cenários sociais diferenciados causa, nos estudantes, um impacto que pode superar o aprendizado pelas vias tradicionais. Esse achado parece evidenciar que aliar a realidade social à experiência acadêmica contribui, como parte de um processo maior (Romanholi, Cyrino, 2012; Sanchez, Drumond, Vilaça, 2008), para a formação de profissionais que respondam mais satisfatoriamente às necessidades da população (Sanchez, Drumond, Vilaça, 2008).

Esse confronto do acadêmico com realidades socioeconômicas e culturais distintas das encontradas em seu grupo social expõe-se aqui reconhecido pelos entrevistados, em sua importância nos quesitos humanistas, críticos e reflexivos, e vão ao encontro das atuais Diretrizes Curriculares Nacionais para os cursos de graduação em Odontologia (Brasil, 2002b). 


\section{Ideia central - A consciência cidadã}

DSC - Tudo o que você faz na universidade, uma monitoria, um projeto de extensão é uma formação extra além da tua graduação, um complemento [...] mas ninguém dá tanto valor a extensão, eu acho que deveriam dar mais [...] é a gente que faz acontecer as coisas, porque tem gente que entra na universidade e sai só pelo diploma, e a gente que tá fazendo um trabalho de retribuição para a comunidade [...] o ser voluntário deveria ser natural pra todos os acadêmicos, já que estamos sendo 'bancados' pelo estado [...] retribuir, essa á a palavra!

Tem-se, hoje, como princípio que, para a formação do cidadão, é imprescindível sua efetiva interação com a sociedade, seja para se situar histórica e culturalmente ou para referenciar a sua formação técnica com os problemas que um dia terá de enfrentar (Medicis, Zago, 2008; Ribeiro, 2005). Certamente, a extensão universitária possibilita essa formação do profissional engajado social e politicamente, com forte reconhecimento do investimento de toda a coletividade e comprometido com a saúde e a qualidade de vida de pessoas e comunidades (Romanholi, Cyrino, 2012). A oportunidade de inclusão nesse espaço privilegiado de produção do conhecimento é aqui evidenciada pelos entrevistados.

\section{Considerações finais}

Esta pesquisa possibilitou uma reflexão acerca da ação extensionista na vida acadêmica e pessoal de estudantes universitários, e seus resultados apontaram importantes direcionamentos.

As concepções acadêmicas perpassaram pelo reconhecimento da enriquecedora oportunidade de acompanhar as condições de vida e de saúde das pessoas inseridas em sua realidade e de vivenciar uma forma de atuação que não se limita à tradicional, o que permitiu, aos acadêmicos, um alargamento em sua visão de futuro profissional. Ainda, os pesquisados consideraram a experiência no campo da extensão um importante agente para o seu processo individual e coletivo de formação pessoal.

\section{Colaboradores}

Cristina Berger Fadel delineou o estudo, elaborou o roteiro para a entrevista, procedeu com a coleta dos dados e realizou a redação do artigo. Danielle Bordin realizou a transcrição dos dados, tratou as informações coletadas e redigiu o artigo. Eunice Kuhn e Luciana Dorochenko Martins contribuíram com a redação do artigo. 


\section{Referências}

ALVES, G.G.; AERTS, D. As práticas educativas em saúde e a Estratégia Saúde da Família. Cienc. Saude Colet., v.16, n.1, p.319-25, 2011.

ARAUJO, M.E. Palavras e silêncios na educação superior em Odontologia. Cienc. Saude Colet., v.11, n.1, p.179-82, 2006.

ARRUDA, W.B. et al. Clínica integrada: o desafio da integração multidisciplinar em Odontologia. RFO, v.14, n.1, p.51-5, 2009.

BRASIL. Ministério da Saúde. Política Nacional de Promoção da Saúde. 3.ed. Brasília: MS, 2010.

Ministério da Saúde. Caderno de Educação Popular e Saúde. Secretaria de

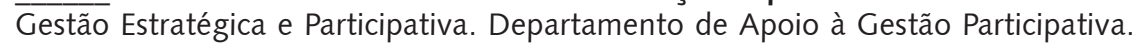
Brasília: MS, 2007.

. Ministério da Educação. Plano Nacional de Extensão Universitária. Fórum de Pró-Reitores de Extensão das Universidades Públicas Brasileiras e SESu/MEC. Edição Atualizada Brasil 2000/2001. Brasília: ME, 2002a.

Conselho Nacional de Educação. Câmara de Educação Superior. Diretrizes curriculares nacionais do curso de Graduação em Odontologia. Diário Oficial da União, Brasília, 2002b. Seção 1, p.10.

CECCIM, R.B. Educação permanente em saúde: desafio ambicioso e necessário. Interface (Botucatu), v.9, n.16, p.161-77, 2005.

COSTA, N.M.S.C. Docência no ensino médico: por que é tão difícil mudar? Rev. Bras. Educ. Med., v.31, n.1, p.21-30, 2007.

DRURY J.; REICHER, S. Explaining enduring empowerment: A comparative study of collective action and psychological outcomes. Eur. J. Soc. Psychol., v.35, p.35-58, 2005.

FERREIRA, R.C.; FIORINI, V.M.L.; CRIVELARO, E. Formação profissional no SUS: o papel da Atenção Básica em Saúde na perspectiva docente. Rev. Bras. Educ. Med., v.34, n.2, p.207-15, 2010.

FEUERWERKER, L.C.M.; COSTA, H.; RANGEL, M.L. Diversificação de cenários de ensino e trabalho sobre necessidades: problemas da comunidade. Divulg. Saude Debate, n.22, p.36-48, 2000.

FREITAS, S.F.T.; CALVO, M.C.M.; LACERDA, J.T. Saúde coletiva e novas diretrizes curriculares em Odontologia: uma proposta para graduação. Trab. Educ. Saude, v.10, n.2, p.223-34, 2012.

HALLACK, F.S.; SILVA, C.O. A reclamação nas organizações do trabalho: estratégia defensiva e evocação do sofrimento. Psicol. Soc., v.17, n.3, p.67-72, 2005.

IERVOLINO, S.A.; PELICIONI, M.C.F. A utilização do grupo focal como metodologia qualitativa na promoção da saúde. Rev. Esc. Enf. USP, v.35, n.2, p.115-21, 2001.

LANZIERI, P.G. et al. "Boa noite, bom dia HUAP!", uma experiência de humanização na formação de profissionais da área de saúde. Interface (Botucatu), v.15, n.36, p.289-97, 2011.

LARA, M.O.; BRITO, M.J.M.; REZENDE, L.C. Aspectos culturais das práticas dos Agentes Comunitários de Saúde em áreas rurais. Rev. esc. enferm. USP, v.46, n.3, p.673-80, 2012.

LEFÈVRE, F; LEFÈVRE, A.M.C. O Discurso do Sujeito Coletivo: um novo enfoque em pesquisa qualitativa (Desdobramentos). Caxias do Sul: EDUCS, 2003. 
LIMA, D.P. et al. A importância da integração universidade e serviços de saúde. Rev. Cienc. Ext., v.6, n.1, p.129-37, 2010.

MEDICIS, F.A.; ZAGO, J.A. A formação do cidadão crítico: análise de uma unidade escolar. Rev. Multidisciplinar UNIESP Saber Acadêmico, n.6, p.190-1, 2008.

MERTON, R.K.; FISK, M.; KENDALL, P.L. The focused interview: a manual of problems and procedures. Glencoe: II Free Press, 1956.

NÓVOA, A. Formação de professores e profissão docente. In: (Org.) Os professores e a sua formação. Lisboa: Publicações Dom Quixote, 1995. p.15-34.

PEREIRA, S.M. et al. Extensão universitária e trabalho voluntário na formação em Odontologia. Arq. Odontol., v.47, n.2, p.95-103, 2011.

REIS, J.T. Trabalho voluntário e os direitos humanos. 2001. Monografia - Pontifícia Universidade Católica de Minas Gerais, Belo Horizonte. 2001.

RIBEIRO, K.S.Q.S. A contribuição da extensão comunitária para a formação acadêmica em fisioterapia. Fisiot. Pesqu., v.12, n.3, p.22-9, 2005.

ROMANHOLI, R.M.Z.; CYRINO E.G. A visita domiciliar na formação de médicos: da concepção ao desafio do fazer. Interface (Botucatu), v.16, n.42, p.693-705, 2012.

SANCHEZ, H.F.; DRUMOND M.M.; VILAÇA E.L. Adequação de recursos humanos ao PSF: percepção de formandos de dois modelos de formação acadêmica em Odontologia. Cienc. Saude Colet., v.13, n.2, p.523-31, 2008.

SANTOS, A.M. et al. Vínculo e autonomia na prática de saúde bucal no Programa Saúde da Família. Rev. Saude Publica, v.42, n.3, p.464-70, 2008.

SANTOS, S.S.C. Currículos de Enfermagem do Brasil e as Diretrizes - Novas Perspectivas. Rev. Bras. Enferm., v.56, n.4, p.361-4, 2003.

SELLI, L. et al. Beneficiários do trabalho voluntário: uma leitura a partir da bioética. Rev. Saude Publica, v.42, n.6, p.1085-9, 2008.

VILLA, E.A.; ARANHA, A.V.S. A formação dos profissionais da saúde e a pedagogia inscrita no trabalho do Programa de Saúde da Família. Texto Contexto Enferm., v.18, n.4, p.680-7, 2009 
Com objetivo de avaliar a contribuição da extensão universitária na formação e história de vida de estudantes de Odontologia, realizou-se um estudo qualitativo, de caráter descritivo-exploratório, utilizando a técnica do grupo focal. O material foi analisado com a técnica de análise do discurso do sujeito coletivo. Os resultados referiram-se ao impacto exercido pela vivência acadêmica em atividades extensionistas nos campos pessoal, profissional e da cidadania. As percepções dos sujeitos revelaram a oportunidade de desenvolvimento e aprimoramento de suas habilidades profissionais, por meio do reconhecimento de distintas realidades de vida, da ruptura do modelo tradicional de ensino e do profícuo relacionamento entre acadêmico, universidade e sociedade. Foram relatados sentimentos de satisfação, realização pessoal, reconhecimento, e de ser um cidadão ativo e crítico. Conclui-se ser a experiência no campo da extensão um importante agente para o processo individual e coletivo de formação acadêmica.

Palavras-chave: Educação Superior. Formação em Odontologia. Grupo focal. Relações comunidade-instituição.

\section{The impact of university extension on academic training in Dentistry}

This qualitative study of descriptive and exploratory nature was conducted with the aim of evaluating the contribution of university extension towards the training and life histories of dentistry students, using the focus group technique. The material was assessed using the collective subject discourse analysis technique. The results showed the impact exerted by academic experience, in extension activities within the personal, professional and active citizenship spheres. The subjects' perceptions revealed an opportunity to develop and improve their professional skills, through recognition of distinct realities of life, through breaking away from the traditional model of teaching and through fruitful relationships between students, university and society. Feelings of satisfaction, personal fulfillment, recognition and being an active and critical citizen were reported. It was concluded that experience within the field of extension is an important agent for the individual and collective process of academic training.

Keywords: Higher education. Dentistry training. Focus group. Community-institution relationships.

\section{El impacto de la extensión universitaria sobre la formación en Odontología}

Se realizó un estudio cualitativo de carácter descriptivo-exploratorio para evaluar la contribución de la extensión universitaria en la formación e historia de vida de los estudiantes de Odontología. Para la recolección de datos fue utilizado el grupo focal y el material fue analizado por medio de la técnica de análisis del discurso del sujeto colectivo. Los resultados se refirieron al impacto ejercido por la vivencia académica en actividades de extensión en los campos personal, profesional y de ciudadanía. Las percepciones de los sujetos revelaron la oportunidad de desarrollo y perfeccionamiento de sus habilidades profesionales, por medio de reconocimiento de distintas realidades de vida, de la ruptura del modelo tradicional de enseñanza y de la provechosa relación entre el sector académico, la universidad y la sociedad. Fueron relatados los sentimientos de satisfacción, realización personal, reconocimiento y de ser un ciudadano activo y critico. Se concluyó que la experiencia en el campo de extensión es un importante agente para el proceso de formación académica individual y colectiva.

Palabras clave: Educación superior. Odontología. Grupo focal. Relaciones comunidad-institución. 